\title{
Awareness and Knowledge of Hazardous and Toxic Building Materials in Adaptation Projects
}

\author{
Zarina Isnin, Sabarinah Sh. Ahmad , Zaharah Yahya \\ Faculty of Architecture, Planning \& Surveying, \\ Universiti Teknologi MARA, Shah Alam, 40450 Selangor, Malaysia \\ sabar643@salam.uitm.edu.my
}

\begin{abstract}
Building adaptation projects may involve hazardous and toxic substances hidden in the building materials. These substances pose dangers to health and safety, disturbing the environment and affecting the projects' turnover. Literature reviews on building adaptation and building materials information management found that vital information are seldom available. This study determines the awareness and knowledge of stakeholders in Malaysian building adaptation projects on the required building materials information. Analysis of interviews with 16 experienced stakeholders revealed the lack of awareness and information on existing building materials that may contain hazardous and toxic substances. Thus, building material information is critically required for future sustainability.
\end{abstract}

Keywords: Awareness and knowledge on building material; Building adaptation; Building material information; Hazardous and toxic building material

eISSN 2398-4295 @ 2018. The Authors. Published for AMER ABRA cE-Bs by e-International Publishing House, Ltd., UK. This is an open-access article under the CC BY-NC-ND license (http://creativecommons.org/licenses/bync-nd/4.0/). Peer-review under responsibility of AMER (Association of Malaysian Environment-Behaviour Researchers), ABRA (Association of Behavioural Researchers on Asians) and cE-Bs (Centre for EnvironmentBehaviour Studies), Faculty of Architecture, Planning \& Surveying, Universiti Teknologi MARA, Malaysia.

DOI: http://dx.doi.org/10.21834/ajbes.v3i9.62 


\subsection{Introduction}

There will be more demands for building materials since a large percentage of the existing building stocks are undergoing some form of building transformation and adaptation exercise (Brandt \& Yong 2011; GBI-Research 2010). Terms such as alteration, upgrading, conversion, refurbishment, renovation or building conservation are often used to describe the building adaptation activities (Douglas; 2006). The construction process of building adaptation may require demolition, dismantling and removal of materials; cutting, drilling, grinding cementitious building materials and even sweeping the workplace. These activities resulted in excessive levels of dust and fumes that are potentially very hazardous. Some of these materials may also contribute to fires, explosions and other accidents if not stored or handled appropriately. Published studies showed several adverse effects caused by some building material substances to health, the environment and the economy (Cassidy (Ed.), 2003; Wilt et al., 2011).

The increasing number of building adaptation projects may create more demands for building materials. The projects may involve new design and new innovative building materials, but the construction processes for building adaptation are more complex. Nonhazardous building materials are found to be stable and in encapsulated form during normal use. However, many studies need to be conducted on building materials that have limited or indistinguishable information on the product substances. Therefore, any individual involved in the projects must be aware and understand the risk and safety of their work.

This study aims to determine the awareness and knowledge of the stakeholders on building materials used in higher education institutions building adaptation projects in Malaysia. The study reviews the issues of building materials in building adaptation projects. It also examines the level of awareness and knowledge of selected respondents on building materials in adaptation works.

\subsection{Literature Review}

The current information on building materials and their hazardous effects, if any, are limited (Levin, 2010). The chemical contents for building materials are not specific enough and sometimes not listed (Willem \& Singer, 2010; Wilt et al., 2011). There are also limited studies on the extent of stakeholders' awareness of the existence and risk of building materials (Willem \& Singer, 2010). It is also difficult to find related studies on the degree of knowledge and action regarding management of building materials in construction and adaptation projects.

In the subject of managing probable existence of hazardous and toxic building materials in building adaptation projects, "awareness of a stakeholder" implies that the individual has heard of it, and has some idea of the related hazardous and toxic building materials in any of the working process from preliminary design until maintenance stages. The individual is adequately informed about a subject, and he/she is conscious of its existence and its broad subject matter. On the other hand, "knowledge" requires a theoretical or practical understanding of a subject. Knowledge of probable hazardous and toxic building materials 
implies that the individual could demonstrate some understanding of the detailed requirement and specifications on managing or handling of these building materials at any stages in building adaptation project.

Through awareness and knowledge on the existence of any hazardous and toxic substances, proper mitigation and prevention plan could be made to ensure the safety and health of employees and other stakeholders. The planning could as well protect the environment. They require safe execution that could be complicated and very technical thus requiring expert assistance (Anumba et al., 2006). It is necessary for all stakeholders involved in the project to plan and implement proper project risk management. Any construction risk relative to certain events or activities is closely linked to awareness of the stakeholders (Zou et al., 1993). The awareness level could be used to assist the construction players and related individuals to become conscious to any potential problems to human and the environment (Hungerford \& Volk, 1990 in Keith, 2011).

Hazardous and toxic materials are harmful both to the inhabitants of the buildings and to the general air quality. Poor affected health conditions may result in loss of concentration at work and fatigue that may increase the risk of accidents. It may cause higher sickness absence from work and incur higher medical bills (Sirajuddin et al., 2001). The effects of these hazardous and toxic substances could be long-lasting and may be transmitted to other parties or locations. They can enter through inhalation (mouth or nose into lungs); ingestion (mouth into the stomach); injection (cuts into the skin) and through dermal absorption (skin membrane). Studies showed that secondary victims such as family members were also affected by harmful dust left on the worker's clothes that were brought home. It was also reported that the inhalation and dermal routes are the most significant to industrial fatalities (Crowl \& Louvar, 2002). There were also cases of cancers, asthma, reproductive problems and even worse, death. Unfortunately, Occupational Safety and Health Act (OSHA) standards do not protect workers, occupants, family and their developing children from all of these adverse effects.

\subsection{Methodology}

In order to gauge the awareness and knowledge of these stakeholders on issues of building materials in building adaptation projects, a preliminary study was conducted to selected experience stakeholders. Theoretically, people will relate to certain events from their own life and experiences (Finger, 1994 in Keith, 2011). Useful feedbacks from these experienced stakeholders will inform on the process of managing building materials and the mitigation plans. Reviews of literature survey became the backbone of this research. Semi-structured interview was used as the primary data gathering technique. The respondents were interviewed about (i) their awareness on the existence of dangers posed by hazardous and toxic building materials, and (ii) their knowledge level of building materials management.

For each interview, a brief introduction about this research including a short discussion was carried out at the beginning. The reason was to eliminate any potential bias response that could affect the reliability and validity of the survey data. Each interview normally took 
about one to two hours and written records were made accordingly during these sessions. The interview questions were divided into two sections and consisted of 30 questions. Section A consisted of 12 questions: six questions measuring the background information of the respondent and six questions focusing on the experience related to building adaptation projects. Section B was designed to identify the awareness and knowledge on hazardous and toxic building materials and management of risk.

\section{Respondents}

The sample for the study was selected from stakeholders involved in building adaptation projects in Klang Valley, focusing on those involved in tertiary education institutions. Interviews were carried out with five representatives of Facilities Management offices comprising of heads of departments with architectural, engineering and quantity surveying backgrounds, three consultants (architects and interior designer), six technical personnel and two building adaptation contractors. The respondents represented a broad spectrum of the building adaptation profession. There were 16 respondents in total. More than two thirds or eleven respondents have related working experience in building adaptation projects between three to ten years. Two respondents have experienced between 11 and 15 years and three respondents have more than 16 years experience. None of the respondents has worked less than three years. The result shows about two thirds of the respondents have carried out more than ten building adaptation projects, a quarter have done between six and ten projects and one respondent has done less than five projects previously. More than two thirds of the respondents have done projects amounting between RM200,001 and RM500,000. Eight respondents have carried out projects that cost more than RM2 million.

\subsection{Findings and Discussions}

\subsection{Awareness on the presence of hazardous and toxic containing building material}

The respondents were asked if they acknowledge the presence of any hazardous and toxic containing building material at their working site (Table 1). Five respondents were aware of the existence of some form of hazardous or toxic building materials such as asbestos ceiling sheets from some of the older buildings and chlorofluorocarbon (CFC) from the older models of air conditioning units. Four respondents reported that their sites had no hazardous and toxic building materials because there was no asbestos based material present. Seven respondents did not know or were unsure.

Table 1: Awareness on the existence of hazardous and toxic material on site

\begin{tabular}{l|c|r|r}
\hline \multicolumn{4}{|c}{ Awareness on existence of hazardous/toxic material on site } \\
\hline & Frequency & \multicolumn{1}{|c}{ \% } & \multicolumn{1}{c}{ Valid \% } \\
\hline Yes & 5 & 31.25 & 31.25 \\
\hline No & 4 & 25 & 25 \\
\hline Do not know & 7 & 43.75 & 43.75 \\
\hline Total & 16 & 100 & 100 \\
\hline
\end{tabular}


They were then asked in detail on the list of materials and chemicals used, produced or released at any time during the construction. Fig. 2 shows that the majority of respondents did not know whether the listed materials are used, produced or released during construction. Some respondents have never even heard of the scientific terms as outlined in the questionnaire.

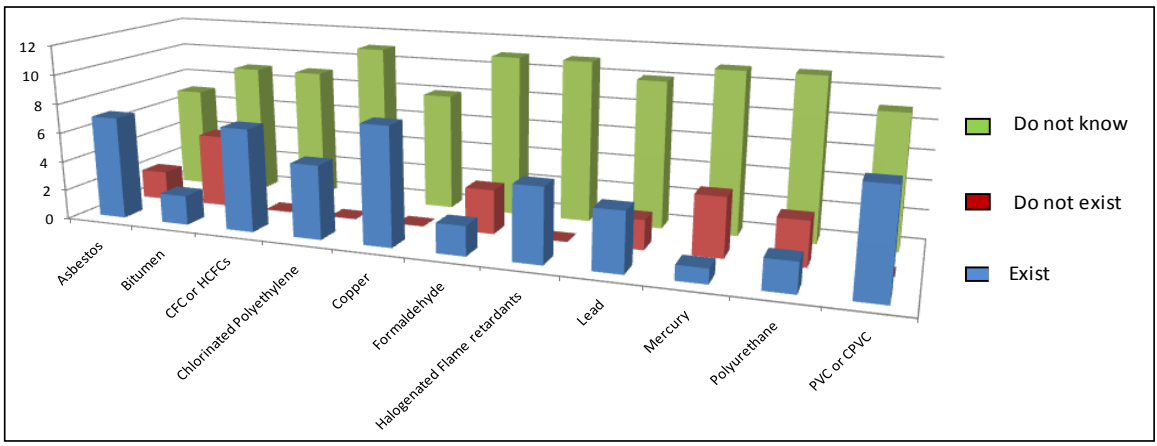

Fig. 2: Awareness and knowledge of the existence of building materials and contents used, produced or released at any time during the construction.

More than two thirds of the respondents reported that as-built drawings, specifications for building materials, construction details and bill of quantities were unavailable before construction work began although these were vital information. Most respondents also have limited awareness and knowledge on the existing information of building materials. According to Ali (2010), clients, consultants and contractors have limited knowledge on the existing building. Risk exposure and maintenance requirements during construction are to be considered. The investigations required reliable information of the building. Information such as as-built drawings, building materials specification, schematic drawings, history of building, maintenance records and building history are required. However, 11 respondents acknowledged that some of the documents are often found to be inaccurate. Modifications have been made to the space. These changes may be due to maintenance or unrecorded alterations carried out by the end-users.

\subsection{Knowledge on Building Adaptation Management}

All respondents acknowledged that visual survey and inspection of the working site are usually performed before any demolition or dismantling work is carried out. It is based on the requirements outlined by acts and regulations to ensure a safe construction site. Furthermore, it is to ensure that no unexpected work is done that will create additional cost and may extend completion time. Visual inspection and survey of the site and surrounding area are conducted according to a checklist. Any defects, damages of the area, potential disturbances or risks of the proposed adaptation area will be noted. Two respondents mentioned the need for inspection findings to be recorded and documented.

Building adaptation work involves different types of activities that are done concurrently 
by different trades of workers at the site. They are often done in confined and congested spaces. The construction workers often do work manually. The working area is usually surrounded with tools, new building materials and construction debris. The construction players are responsible to ensure that safety and health of the construction site conforms to legislation requirement, approved standards, code of practice, guidelines, specifications and contractual requirements.

Unfortunately, there was no survey or inspection made on suspicious hazardous and toxic building materials either on the existing site or for the proposed new project. Inspections seldom involved partial destruction to find uncertain contents of concealed materials, although these findings could eliminate the risk of hidden dangers to stakeholders. Several studies indicated the importance to locate and describe any potential hazardous and toxic building materials in the proposed building adaptation area (Department of Standards Malaysia, 2010). The inspection may be carried out within wall cavities and enclosed building structures to find hidden materials. It may require partial destruction of the finishes before the actual building adaptation project and is usually done whilst the building is not occupied. These pieces of information could assist in the tendering process for the removal of nongreen building materials from the building before work commences. The findings could eliminate the risk of exposure to workers and the surrounding environment.

Twelve respondents (75\%) reported that they had no knowledge on proper removal of hazardous/toxic building materials. Four respondents comprising of a professional architect, designers and client representative with more than ten years experience had the required knowledge of proper removal of hazardous building waste. This knowledge should be based on the recommended procedures such as separation of waste; certified and authorised personnel should do proper removal techniques and the removal. Contractors usually do not plan their construction work properly (Ali, 2010; Anumba et al., 2006) even when the work are more complicated (Douglas, 2006). For this study, the client and consultants have limited knowledge on proper management of building adaptation projects that may involve nongreen building materials.

\subsection{Conclusion}

Building adaptation projects encounter many challenges especially with acquiring information on the existing building and space as well as building materials. The results from interviews with selected experienced building adaptation players showed that most of them lacked awareness and knowledge on probable existence of hazardous and toxic building materials. Good decisions can only be made based on accurate information. Risk control procedures are required to be in place since a large percentage of building materials found today consisted of hazardous and toxic contents that can cause chronic health problems to stakeholders. Documentation of completed project is required, as the information will be used for any future building adaptation project. The information and specification could then be extended and modified to include any new requirements and amendments on any inconsistencies or redundancies. Although many of these building materials are hidden under the superficial interior designed space, important information are required to ensure the safety and health of human beings for future sustainability. 


\section{Acknowledgement}

The authors would like to thank Research Management Institute of Universiti Teknologi MARA for supporting this research under the Excellence Research Grant and the Research Intensive Faculty grant scheme.

\section{References}

Ali AS. (2010) Design information in managing refurbishment projects in Malaysia. International Journal of the Physical Sciences, 5(6), 768-773. Retrieved from http://www.academicjournals.org/lJPS

Anumba C, Egbu C., Kashyap, M. (2006) Avoiding structural collapses in refurbishment - A decision support system (HSE Research Report 463). Leicestershire.

Brandt T. \& Yong J. (2011) Market Watch Malaysia 2011 Construction Industry (Malaysian-German Chamber of Commerce - The Construction Sector).

Cassidy R. (Ed.) (2003) White paper on sustainability: A report on the green building movement. Building Design \& Construction. Retrieved from www.bdcmag.com

Crowl DA \& Louvar JF. (2002) Chemical Process Safety - Fundamentals with Applications, $2^{\text {nd }}$ Ed., Pearson Hall. Department of Standards Malaysia 2010 Draft Malaysian Standard - Demolition of buildings - Code of Practice (First Edition).

Douglas J. (2006) Building Adaptation 2nd Edition. Building (pp. 1-47). Butterworth-Heinemann.

Dürkop J, Horn W, Englert N, \& Plehn W. (2007) Building products: Determining and avoiding results from a research project. Bundesanstalt für Materialforschung und -prüfung (BAM). Retrieved January 18, 2011, from www.umweltbundesamt.de

GBI-Research (2010) Green buildings market to 2015 - incentives for green initiatives and minimum level of standards to boost growth opportunities. pp. 1-9, Reference code: GBICT00321CR.

Keith K (2011) Dangerous decor: Consumer knowledge of health risks within interior spaces. Master Thesis. San Jose State University. Retrieved from http://scholarworks.sjsu.edu/etd_theses/3934

Levin H. (2010) National programs to assess IEQ effects of building materials and products (pp. 1-50).

Sirajuddin H, Roslinah A, Rampal KG, Kuppusamy I, Rohna R, Aziz M, Aw TC, et al. (2001) Notification of occupational and work-related diseases and poisonings in Malaysia, 1997-1998. The Medical journal of Malaysia, 56(1), 25-31. Retrieved from http://www.ncbi.nlm.nih.gov/pubmed/11503292

Willem H, Singer BC. (2010) Chemical emissions of residential materials and products: Review of available information.

Wilt CA, Monaco JK, Geibig JR, Hite A. (2011) Identification and analysis of product/ chemicals exchange information within the building product sector.

Zou PXW, Zhang G, Wang J. (1993) Identifying key risks in construction projects: Life cycle and stakeholder perspectives related past research and risk classification. 